\title{
Empowerment of Student Social Worker-Reading between the Lines
}

\author{
Poonam Gulalia \\ Tata Institute of Social Sciences, Mumbai, India \\ *Corresponding Author: poonam.gulalia@tiss.edu
}

\begin{abstract}
In the last two decades, in particular social work, educators and practitioners have been dealing with issues such as race, class, gender, sexuality, age and (dis) ability which are critical to understanding people's lives, contemporary issues and possibilities for change. Fieldwork is a central component in social work education. Many students perceive their field education as the most important part of their studies wherein they gain experience in direct practice and develop their professional identity. Many Schools of Social Work struggle to find the 'best fit' between learning in the field and in the classroom. Although supervision is the key to student learning, it is essential to understand the perspectives of students at various stages of learning on field related issues. Moreover, students are encouraged to question 'cherished beliefs and assumptions' by becoming witnesses to social injustices. Being a professional requires learning life-long skills which further requires a different kind of investment on the part of educator. Self-assessment and peer assessment among supervisors and faculty must be encouraged. One also needs to discuss the tension and power relationships between ourselves and our beneficiaries. The million dollar question is as to where are our service users and clients positioned within fieldwork. The paper attempts to throw light on some of these dilemmas and suggest possible ways of addressing the challenge. Qualitative Research Methodology has been utilized in this paper. It has involved an understanding of processes, events and relationships in the context of the social and cultural situation.
\end{abstract}

Keywords Student Learner, Empowerment, Learning Environment, Life-Long Learning, Service User

\section{Introduction}

Fieldwork practice provides an opportunity to the students to connect theoretical education with fieldwork practice. Kirke et al (2007) reported that fieldwork practice is anchored in the mission, vision, and goals of the social work training program. It has been seen that it occurs in settings, agencies and placements which reinforce student's identification with the values and ethics of the social work profession (Kirke et al, 2007). Fieldwork also develops in students, skills that enable them to respond appropriately to the needs of clients. Safari(1986) stated that " in the field, the student comes into contact with needy people, their problems, their reactions to the problems and their attitudes towards social workers and thus the student discovers his/her ability to help"(1986:74). It is through observation and doing the job and feeling responsible for the job of helping people to cope with their problem that social work student acquire skills. Likewise, fieldwork is designed to give the student exposure and experience on the functioning of social welfare agencies. It is through opportunities to practice that students assimilate principles, values and ethics of the profession and feel empowered. It enables them to be a professional in the true sense of the term.

'Empowerment' refers to the process by which people gain control over the factors and decisions that shape their lives. It is the process by which they increase their assets and attributes and build capacities to gain access, partners, networks and/or a voice, in order to gain control.

\section{Student Social Workers Empowerment through Field Work}
a) Fieldwork as an essential learning environment
b) Building and maintaining relationships
c) Making Learning a Conscious Process
d) Role of Fieldwork for Student Learning

\section{a) Fieldwork as an essential learning environment}

A central goal of all professions is the alignment of theoretical learning into practice. However, one's experience and observations reveal that a number of social work students fail to grasp the basic principles of theoretical application. The fact of the matter is that practice informed by theory distinguishes professional social work from voluntary work. 
In fieldwork practice students are usually expected to apply the professional knowledge and theory they have learnt. However, social constructionists believe that knowledge is a product of social discourse which is shaped in the context of power relationships. While adopting the principles of social constructivism it is essential that fieldwork supervisors encourage students to question the assumptions of the theory used, to critique the applicability of the theory in the context of the placement and to explore the alternate use of other theories.

In every fieldwork setting, the student intern is placed in a context which allows dialogue and interactions between students and clients. It is in this backdrop that the negotiation of meaning occurs, cultivating a skeptical attitude toward knowledge in the context of fieldwork (Lit \& Shek, 2007). Lit \& Shek emphasize that although fieldwork is the 'doing' component of social work education, it is basically concerned with ' knowing' In engaging with clients students participate so as to co-construct the meaning and narrative with the clients. It is the role of the supervisor then to enable the supervisor to become aware of his/ her own values and assumptions and the effects it has on the meaning-making process.

It is also an integral requirement that fieldwork supervisors play an expert role in training the students to become competent social workers. However, social constructionists opine that the individual is the active meaning-maker and the social worker is involved in this process through this on a 'more 'equal basis. (Lit\& Shek, 2007:362)

Fieldwork practice also draws heavily from the strengths-based perspective because in fieldwork the focus of practice is on how students approach their tasks, the skills, the knowledge, the attitudes and the resources which are utilized for training and learning. Learning takes place within the context of relationship. Several stakeholders are involved in this process: the University/ Colleges where learning takes place, social work educators and social work agencies. Davys and Beddoe (2000:437) believe that to provide the student with an opportunity to put theory into practice is the primary focus of the 'field' experience. However, there is often lack of connection between theories learned in the classroom and field experiences (Teigiser, 2009).

The environment in which learning takes place at the level of the field is constantly changing. One needs to take into consideration the environment where learning takes place. Field education has been affected by the fact that there are now increased workloads of agency staff, there are problems in funding and there are rapid changes in social work itself. Less time is available to guide and develop students 'learning. It is also necessary to assess the theoretical knowledge base of agency-based supervisors.

It need be stressed that signature pedagogy is a central form of instruction and learning to socialize students to perform the role of a practitioner - it contains pedagogical norms with which to connect and integrate theory and
practice"(CSWE, 2008, p.8). Specifically, students learn to practice the profession through active involvement with "real" experiences in which they perform a service or helping role, and opportunities are provided for study of their practice. The first process involves subjective reflection about students' understanding and reactions to the practice situation (Bogo \& Vayada, 1998). The second process involves conceptualization of the practice situations and interventions, through making connections to theory, providing conceptual frameworks and supplying explanations from the field instructor (Fortune, McCarthy \& Abramson, 2001; Knight, 2001) Insights obtained from these processes are then used to plan interventions for subsequent practice.

\section{b) Building and maintaining relationships}

Relationship is one of the most important aspects in a supervisory-supervisee situation. The field instructor-student relationship is the context for learning and the relationship is expected to be both supportive and challenging (Fortune et al, 2001; Knight, 2000) ${ }^{\mathrm{i}}$. A rich educational and empirical literature on field education spells out pedagogical processes, techniques and tasks for field instructors (Bogo, 2005; Bogo \& Vayada, 1998; Caspi \& Reid, 2002; Fortune et al, 2001; Hendricks, Finch \& Franks, 2005; Raskin, 1989, Wayne \& Cohen, 2001). These are yet to be systematically incorporated in all students' learning experiences in field education. So the first problem in teacher education as spelt out by Shulman (2005) is the uncertainty of the pedagogical models of practice. Moreover, field instructors do not have a "shared view of how to best impart knowledge" (Shulman, 2005) .They vary in their use of written materials and supervisory formats and schedules. Content varies in the balance between theoretical and practical emphases and in the analyses of past actions versus planning future strategies (Wayne, 1988; Wayne, Bogo \& Raskin, 2006).There is a wide variation in the nature of student assignments. Some students are asked to observe seasoned practitioners while others are sent into solo practice experiences from the start (Fortune\& Kaye, 2002; Homonroff, 2008; Mumm, 2006). As Gambrill (2001) has pointed out, in order to assess students' ability to perform the core functions of the profession effectively, instructors must examine their interactions in practice situations.

Signature pedagogies expect students to be both active and interactive. Students are accountable not only to teachers but also to their peers in their responses, arguments, commentaries and presentations of new data. The reality is that in many Schools of Social Work, many students go through their entire education without any formal discussion with another student about any aspect of their field assignments. Student-to-student accountability, as such, is not in-built into the fabric of social work field education. Moreover, as Shulman (2005) has explained students must experience "adaptive anxiety" as a necessary feature of learning in signature pedagogy. "Uncertainty, visibility and accountability inevitably raise the emotional stakes of the 
pedagogical encounters". One needs to acknowledge that in order that students learn they must be emotionally invested in their work and experience some anxiety. Surprisingly, field instructors are concerned about reducing student anxiety (Gelman, 2004; Wayne \& Cohen, 2001; Zosky, Unger, White\& Mills, 2003).

The social work literature is replete with the need for modifications to field education as it is currently implemented in the face of the changing socio-economic context of social work education. A major modification in field education as currently carried out would be the addition of student-to student accountability and greater student visibility of their field education performance.

The individual conference as is currently structured and practiced in most Schools of Social Work provides no opportunity for student-to-student accountability and limits performance visibility. Group Conferences as are being practiced in few Schools of Social work attempts to address this issue. When the profession relied heavily on psychodynamic theory to inform direct practice the one-to one individual supervisory conference was viewed as a critical component of the educational experience (Wijnnberg \& Schwartz, 1977). The group process (with Group Conferences as part of that) has the potential to foster greater in-depth critical thinking and integration of knowledge, theory and practice than what can usually result from the student-field instructor exchange alone. Field seminars, group supervision or what Teigiser (2009) terms opportunities for "collective learning" (p.139) could emerge as major educational arenas for the study of each students practice. Peer learning is a highly valued component of adult learning (Knowles, 1980). Expanding its use in social work field education would bring the added benefit of providing students with both the skills and the mind-set to engage in peer evaluation and accountability. Unless a space/atmosphere is created where the supervisee feels it is acceptable to make mistakes, there will be no feeling of trust. The goal of supervision is to make the supervisee feel confident to function independently.

\section{c) Making Learning a Conscious Process}

The process of how social work students become competent social workers has been investigated by Fook and colleagues (1994) and Ryan et al (1995). Developing people as individuals enables learning methods to fit each person's own preferred learning styles and natural preferences. Experiential learning takes into account multiple intelligences and these must be acknowledged and respected.

The student has to be helped to develop capacity to monitor and evaluate his own practice. He has to learn not only what and how but also why he does his task in a particular way. This is especially important as a learning principle in the field where instructors are apt to concentrate on what is the situation, what is to be done and how, rather than on why it has to be done in the first place, e.g. why organize a day camp as a program and in what way is it a tool for achieving some overall agency objectives.
Making learning conscious helps to promote transfer of learning from one situation to another. We are preparing a professional to practice for several decades in a changing context. He/ she must therefore, learn to think for himself, to appraise a situation and decide what needs to be done. There are no fixed boundaries for his practice. We are not teaching a trade but preparing a professional who will work in a fluid situation requiring his own judgment. Thus, in field work, a visit to the dropout from school lends itself to much teaching around the child and his family and the immediate solution required returning him to school. On the other hand, we must also help the student link it to the national problem of wastage, the effects of poverty, the inadequacy of the educational system in relation to its aims, content and methodology, the problems in learning of first generation learners, and such other concepts which the student needs to know.

Teaching, therefore, needs to be selective and areas must be prioritized as there is too much to teach. Therefore, it is not necessary to teach content in breadth, but selectively teach a few concepts in depth. One current challenge of social work education involves two tasks: teaching evidence - a task performed in the classroom - and training towards clinical decision making that occurs as part of fieldwork (Savaya et al., 2003). Alongside the debate on the nature and costs of field education (e.g. Pelech et al., 2009) many schools of social work struggle to find the optimum balance between learning in the field and in the classroom (Homonoff, 2008). By developing people as individuals one develops people's self-confidence, self-esteem, personal strengths and a sense of purpose which improves attitudes, emotional well-being and life balance.

\section{d) Role of Fieldwork for Student Learning}

Social work classroom-based learning is linked to fieldwork in practice. It is in fieldwork practice that the knowledge learnt in the classroom is assimilated in real life situations. This is what ultimately shapes the professional identity of the student intern. Researchers including Coulshed and Orme (2006) and Parker (2007) note that there is a lack of integration between social work theory and fieldwork practice. Also, there is a lack of standardized instruments for assessing fieldwork practice which includes learning and performance (Bogo \& Globerman, 2003).

Another major problem with integration of theory and practice in Social Work is the attitudes of students before they enter practice. (Redmond, Guerin and Devitt, 2008) The performance of students in fieldwork is crucial as it relates to the fieldwork agency, the setting and the skills learnt.

Selahu-Din(2003:13) define a theory as a group of related concepts and propositions based on facts and observations, that attempt to define and predict phenomenon such as behavior, events, situations and attitudes.

Quality fieldwork practice occurs when learning is optimal and can be individualized to the students' learning needs. In this context, it is believed that social work fieldwork practice is designed, supervised, coordinated and 
evaluated on the basis of criteria by which students demonstrate the achievement of program objectives (Pardeck, 2005:116)

Self-assessment and peer assessment among Supervisors and faculty must be encouraged. Reflective learning and critical thinking imply that varied strategies be used for enhancing learning which includes self-assessment and peer assessment.

Crips, Lister and Duton (2006:727) state that self-assessment and peer assessments focus on the students' capacities to assess themselves, to make judgments about their learning and to evaluate what has been learnt. This involves sorting out the power equations between Supervisors, Supervisees and field contacts, developing anti-oppressive practice and enabling students to take responsibility for their own learning.

There is a dire need for entry level assessment of students who opt for the social work profession both within practice agencies and academic institutions (Furness \& Gilligan 2004:467). This enables enhancing and promoting student learning, ensuring competence, monitoring student growth, and identifying further educational and practice needs (Hay \& o'Donoghue, 2009:43) it also ensures that the interests of service users, clients and beneficiaries are safeguarded.

Summative assessment is a measure of the students' performance or level of achievement at the end of the sequence of study. Hay and O'Donoghue (2009:44) state that all the institutions require written documentation for summative assessment purposes. These documents address the achievements of the learning outcomes, the areas of strength and future development of the student. It is essential to address the following concerns:

1. What has gone well?

2. What has not gone well?

3. What does the student see as his/ her learning needs?

4. What does the Supervisor see as the student's learning needs?

5. What has the student learnt from these experiences?

6. What will be done differently?

7. What does the Supervisor feel the student could have learnt?

Needless to say, formal supervision is a time for exploring practice, a time for learning, where the real objective is facilitating the students' growth. Supervision must ensure that they acknowledge the importance of these sessions and allocate appropriate time for them.

As Supervisors and practice educators, we need to

- Reflect in and on practice

- Recognize the importance of professional development as an educator

- Solicit feedback from students

- Anticipate emotion and conflict

- Prepare students for the possibility of conflict

- Engage in recovery and repair.

The ultimate goal of giving feedback is to be able to receive it and integrate it. Secondly, the purpose is to help the student improve skills, to equip self with necessary knowledge and to develop appropriate attitudes. The supervisee must feel understood, respected and valued. The language, tone of voice and phrases used should reflect that it is the Supervisor's own opinion and not the ultimate truth. One needs to find ways to be encouraging and supportive, to provide a safe environment and to be a mentor rather than being judgmental. It is also essential to be as concrete as possible and to watch non-verbal behaviours besides listening to what the supervisee might want to say. Feedback should be given as close to the event as possible and early enough for the supervisee to do something about it. There needs to be a balance between positive and negative comments.

\section{Engaging with Service Users in Social Work Education Training}

Service users' involvement is now understood as an important aspect of Social Work education in the UK context (Branfield, 2009; Taylor et al, 2009). The rationale for such involvement is that the everyday experiences of service users are recognized to be fundamental to equipping professionals in making with key aspects of knowledge and expertise to improve services (Beresford 2000; Anghel and Ranon, 2009) This is very important for social work students in the early stages of their training (Cooper and Spencer-Dawe, 2006) and assists in their development of self-awareness and communication skills (Skilton, 2011). If we truly believe in the concept of community empowerment, we need to ensure that our student learners engaging with service users reverse the process of learning so that the social work realizes its meaning.

One needs to discuss the tension and power relationships between ourselves and our beneficiaries. The million dollar question is as to where are service users and clients positioned within fieldwork. The researchers' understanding is that service users operate within a cultural context that they had little part in shaping and this tends to reinforce the asymmetrical power which characterizes relationships between professionals and those who use their services. Service users prioritize social work practice which: is participatory in process and purpose focused on supporting independent living and participation rather than dependence, offers continuity, is flexible and person-centered, connects the personal with the social and political, offering personal/emotional and practical support, addresses rights, risks and their complex interrelations and is based on inclusive understanding of knowledge which includes the experiential knowledge of service users and the practice knowledge of face to face workers.

They value social work practitioners who support them to work out their own agendas with them, give them time to sort things out, are available and provide continuity of support, are reliable and deliver, are responsive, have a good level of knowledge and expertise and value the expertise of the 
service user.

This applies to all groups of service users in relation to all forms of social work. Service users value the support that social workers can offer as well as their ability to help them to access and deal with other services and agencies. They welcome a 'hands-on' approach, which takes account of both personal and social issues and their complex interrelations (seeing this as what defines social work), rather than the social worker merely acting as a referral agent.

There still seems to be widespread lack of understanding about the roles and tasks of social work among both public and service users. Social work is concerned with support, control and making personal change. The first is valued by service users; the others are contentious and particularly in work with children and families seem to be occupying an increasingly central role in social work

In 2012 a study of service user and carer involvement in social work was conducted by Rosemary Rae, University of Huddersfield in UK Her doctoral thesis was on Trust, Power and the New Professionalism: A Case Study of Service User and Carer Involvement in the Selection of Social Work Students. In the study service users were involved in various aspects of design and delivery of education and training. A range of perceived benefits of involving service users' stereotypes of service users ensures that the priorities of service users are reflected in the program and it also provides an opportunity for service users to share experience and expertise besides ensuring that service users feel valued

However as Laberee (2000) observed there are issues which need to be recognized and we need to 'step outside' in order to get a new understanding of the 'inside'. We need to understand the tensions and power relations which operate between professionals and clients. Bourdieu (1998) and Abbott (2005) provide frameworks which are useful in analyzing the tension between service user involvement and social work professionalism Abbott uses the concept of linked ecologies and how differing ecologies can compete for jurisdiction over particular areas of expertise. In this scenario we could isolate the political ecology and the professional one. In Abbott's typology (2005), the purpose of these competing relations between professional actors and key institutions and with professionals competing for and sometimes absorbing, (or losing) areas of jurisdiction, is self-aggrandizement.

Moreover, service users are required to operate within a cultural context wherein asymmetrical power relations are nurtured and strengthened and herein lies the paradox. It is suggested that people who use services should

- Influence the planning of services

- Have their interests, strengths and built on by services

- Be active partners in finding and developing solutions to problems

- Be able to get the help they need when they need it

- Have a consistent and reliable relationship with their worker
Last, but not the least, we need to admit that social work services don't have all the answers. We need to work closely with other providers in all sectors to find new ways to design and deliver services across the public sector.

The profile of rights needs to be raised in an accessible and acceptable way, without necessarily entering into situations of conflict. Even within the broad community of people using adult social care services, different people have different levels of power over their lives, over the decisions made about them and the choices and risks they can take.

\section{Conclusions}

In field training, the notion of 'integration' has long been emphasized and students are evaluated in terms of how well they can 'integrate' theories with practice. However, it is not entirely clear how 'integration' manifests in practice and how students can develop this ability in field training (Pilalis, 1986; Reay, 1986; Saleebey, 1989). At the same time, the mode of learning in field training is by nature more experiential than cognitive.

As students' field learning is a private experience, we feel that the principles of self-directed learning may well provide the basis on which to ground fieldwork instruction. Self-directed learning values students' ownership of their learning and yet such ownership is possible only if students will not be assessed to their disadvantage for the mistakes they may have made in the learning process. First, we should help prepare our students for the sort of learning experiences they are going to undertake before the commencement of their fieldwork placement. In other words, a good orientation program for students is an indispensable part of fieldwork instruction. Furthermore, the orientation program should also prepare teachers for what their students may bring to the teaching-learning process in field training. Second, as practice teachers, we should articulate our conception of field training in terms of how we teach, what we expect students to learn, and toward what end we teach and students learn. It is through such articulation among ourselves as a community of practice teachers that we may be able to sustain a critical discourse on fieldwork instruction such that, in the long run, we may arrive at a better understanding of the science and the artistry of fieldwork instruction.

The present focus of fieldwork instruction on giving direct guidance and corrective feedback to students' performance in their professional role is clearly self-defeating. A key fieldwork education task, along with integration of theory and practice, is the development of reflective practice. The learner is central to the process throughout and the facilitator provides the learner with a service. The facilitator must understand that student learners can make best use of their opportunities if they are ready, willing and able to become personally involved in the learning process. Student learners need to be prepared to actively develop their understanding and critique and evaluate the messages in their context and 
then apply that for appropriate learning,

We need to repeatedly find or create experiential learning opportunities and also need to build the students' confidence before addressing attitudes and behaviour. The MA Dissertation study undertaken by Dino (2013) at University of Limpopo on aligning theory with practice addresses some very pertinent needs. These include engaging with trainers and field agencies on whether they think there is a connection between theory and practice. If so how? We also need to evaluate their understanding of how they apply theory or theories. Also, what factors in their opinion hinder translation of theory into practice? In addition, understanding their personal attitude towards fieldwork practice and the understanding of the supervision they received will go a long way in doing justice to fieldwork in contemporary times.

Assessment is no doubt essential during fieldwork training but it is also mandatory that we understand the measuring tool used for the same. Since fieldwork training takes place within the context of the supervisory relationship, we need to assess and review the kinds of attitudes students display towards fieldwork practice. Last, but not the least, how do agency supervisors and field contacts update themselves regarding the latest developments in social work curriculum?

There is a need to develop a fieldwork curriculum enlisting the competencies we think the students need to learn, besides outlining their learning goals and the learning outcomes. These competencies could include:

- Identification with social work profession

- Application of ethical principles in practice

- Application of critical thinking in practice

- Incorporating diversity into practice

- Advocating for human rights and social justice

- Engaging in informed research

- Application of knowledge of human behavior in the social environment

- Engaging in policy practice to advance social and economic well-being

- $\quad$ Responding to contexts that shape practice

- $\quad$ Engaging, assessing, intervening, and evaluating with individuals, families, groups, organizations and communities

A weekly Supervision Journal could be maintained enumerating the following:

Activities this week:

- What did I observe/learn?

- How did I feel?

- What questions or thoughts do I have?

- How have I integrated field and theory?

- What practice behaviors did I demonstrate?

- Issues, concerns or conclusions

Learning outcomes would consequently include the following:

- Knowledge about the tasks and roles of social workers and other professional groups in the given organization
- Application of theoretical knowledge and current research in practical social work

- Analysis of how theoretical knowledge, profession-specific proficiencies and individual competence are integrated into the social workers' professional practice

- Communication with client groups and other actors

- Critical evaluation of the theoretical aspects of social work in the given organization

- Reflection on one's own individual influence on how social work is portrayed

- Reflection on and identification of what aspects in one's own professional competence which need to be developed

As such, the field of social work may not necessarily be concerned with what new critical social work students are, but instead what we can do with them. Many critical social work educators strive to facilitate learning environments that privilege: the active creation of collective knowledge over the passive giving and receiving of pre-determined knowledge; contradiction over certainty, surfacing assumptions over learning "the facts," searching for understanding over finding the truth; exploring questions over finding answers; staying with discomfort over seeking comfort; dialoguing over debating; working collaboratively over working competitively. (Campbell \& Baikie, 2012).

\section{REFERENCES}

Abbott, A. (1995) 'Boundaries of Social Work or Social Work of Boundaries? The "Social Service Review" Lecture' in Social Service Review, 69 (4) pp. 545-562

Anghel R and Ramon S (2009) Service users and carers' involvement in social work education: lessons from an English case study. European Journal of Social Work 12 (2), 185-189

Bourdieu, P. (1998) Practical Reason On the Theory of Action. USA, Ca: Stanford university Press

Bogo,M.\& Vayda, E.(1998) The practice of field instruction in social work: Theory and process(2nd edition).New York: Columbia University Press

Branfield, F (2009) Developing user involvement in social work education. Social Care Institute for Excellence, London

Caspi, J., \& Reid, W. J. (2002). Educational supervision in social work. New York, NY: Columbia University Press

Cooper H and Spencer-Dawe E (2006) Involving service users in interprofessional education narrowing the gap between theory and practice. Journal of Interprofessional Care 20 (6), 603-617

Council on Social Work Education. (2008). Educational policy and accreditation standards. Alexandria, VA: Author

Crisp, B. R., P. Green Lister, and K. Dutton( 2006) "Not Just Social Work Academics: The Involvement of Others in the Assessment of Social Work Students." Social Work Education: The International Journal 25 (7): 723-34. doi: 10.1080/02615470600905952 [Taylor 


\section{\& Francis Online]}

Davys, A. and Beddoe, L. (2000) 'Supervision of students: a map and a model for the decade to come', Social Work Education 19(5): $437-44$

Fortune, A. E., McCarthy, M., \& Abramson, J. S. (2001) Student learning processes in field education: Relationship of learning activities to quality of field instruction, satisfaction, and performance among MSW students. Journal of Social Work Education, 37, 111-124. Gar, M., Marnes, G., \& Ganshovsky, M. (1995). Field instruction Jerusalem, Israel: The Hebrew University (Hebrew).

Furness, S. \& Gilligan, P. (2004) Fit for Purpose: Issues from Practice Placements, Practice teaching and the Assessment of Student's Practice, Social Work Education, 23,465-479.

Globerman, J. \& Bogo, M. 2003: Changing times: Understanding social workers' motivation to be field instructors. Social Work, 48(1):65-73

Hay, K., \& O’Donoghue, K. (2009). Assessing social work field education: Towards standardising fieldwork assessment in New Zealand. Social Work Education, 28(1), 42-53

Hendricks, C. O., Finch, J. B., \& Franks, C. L. (2005). Learning to teach, teaching to learn. Alexandria, VA: CSWE Press.

Holtz-Deal, K. \& Clements, J, A. (2006).Supervising students developmentally: Evaluating a seminar for new field instructors. Social work education, 42 (2):291 - 306

Homonoff, E.(2008) The Heart of Social Work: Best Practitioners Rise to Challenges in Field Instruction. Clinical Supervisor, 27(2), 135-169

IASSW/IFSW 2004, Global Standards for Social Work Education and Training, http/www. iassw/aiets.org

Jarvis, Holford and Griffin, 1998, The Theory and Practice of Learning, Korgan Page, London.

Lacerte, J., J.Ray \&L.Irwin(1989), Recognizing the educational contributions of field instructors, Journal of Teaching in Social Work 3(20, 99-113

Labonté R. and Laverack G. (2008) Health promotion in action: from local to global empowerment.

Kirke, P., Layton, N \& Sim, J (2007). Informing fieldwork design: Key elements to quality in fieldwork education for undergraduate occupational therapy students Australian occupational journal, 21, 14-21.

Knight, C. (2000) Engaging the student in the field instruction relationship: BSW and MSW students' views. Journal of Teaching in Social Work, 20(3/4), 173-201.

Kolb, David A. "Learning and Problem Solving: On Management and the Learning Process," from KoIb, David A; Rubin, Irwin and McIntyre, James M, ed.. Organizational Psychology: A Book of Readings. Englewood Cliffs, NJ: Prentice-Hall, Inc., 1974.

Koprowska, J.(2010) Communication and Interpersonal Skills in Social Work, 3rd Edition, Exter: Learning Matters

Laberee, R. (2002) 'the risk of 'going observationalist': negotiating the hidden dilemmas of being an insider participant observer', Qualitative Research, 2 (1) pp. 97-123

Lacerte, J., J.Ray \& L.Irwin,( 1989), Recognizing the educational contributions of field instructors, Journal of Teaching in Social Work, 3(2), 99-113

Lefevre, M (2010) Communication with Children and Young People: Making a Difference. Policy Press, Bristol

Lit, S. \&. L. Shek, D.T. (2007). Application of social constructionist principles in field practice teaching in a Chinese Context. Social work education, 26 (4):359-375

Manthrope,I(2000), Developing careers: contributions to social work training', Social Work Education, Vol.19, no.1, pp19-27

Mumm, A. M. (2006). Teaching social work students practice skills. Journal of Teaching in Social Work, 26(3/4),71-89

New Dictionary of Social Work (1995) Cape Town: CTP Book Printers.

Pardeck, John T. (2005), Children's Rights: Policy and Practice. New York: Haworth Press.p276

Parker. J. (2007) Developing effective practice learning for tomorrow's social workers. Social work education, .26, (8):763-779

Raskin, M. (Ed.). (1989). Empirical studies in field instruction. New York, NY: Haworth Press

Redmond, Bairbre; Guerin, Suzanne; Devitt, Catherine(2008) Attitudes, Perceptions and Concerns of Student Social Workers: First Two Years of a Longitudinal Study ,Social Work Education, Volume 27, Number 8, December 2008, pp. 868-882(15)

Safari, J. (1986) The Role of Fieldwork in the Training of Social Workers for Rural Development in: Social Development and Rural Fieldwork, Proceedings of a Workshop held 10-14 June, Harare. Zimbabwe. Journal of Social Development in Africa, pp 74-80

Savaya, R., Elsworth, G., \& Rogers, P. (2008) Projected sustainability of innovative social programs Evaluation Review, 32, $478-50$

Shulman, L. S. (2005a). Pedagogies of uncertainty. Liberal Education, 91(2), 18-25.

Shulman, L. S. (2005b). Signature pedagogies in the professions. Daedalus, 134(3), 52-59.

Skilton CJ (2011) Involving experts by experience in assessing students' readiness to practise: The value of experiential learning in student reflection and preparation for practice. Social Work Education 30, 3, 299-311

Taub, Barry R.; Porter, James E.; Frisch, Giora R. The Clinical Supervisor, Vol 6(2), 1988, 75-84.

Taylor I and Le Riche P (2006) What do we know about partnership and service users and carers in social work education and how robust is the evidence base? Health and Social care in the Community 14 (5), 418-425

Taub, Porter \& Frisch, 1988 Training for psychotherapy supervisors: A supervision traineeship program.

Teigiser, K.S. (2009). Field Note: New approaches to generalist field education. Journal of Social Work Education, 45, 139-146

Veronica Coulshed and Joan Orme, Social Work Practice (Fourth Edition), British Journal of Social Work, Basingstoke, Palgrave, 2006, pp. xiii +322

Wayne, J., \& Cohen, C. S. (2001). Group work education in the 
field. Alexandria, VA: Council on Social Work Education

Wilson, G. And Kelly, B.(2010) 'Evaluating the Effectiveness of Social Work Education: Preparing Students for Practice Learning'. British Journal of Social Work Advance Access published

White, E, V. \& Queener, J. (2003). Supervisor and supervisee attachments and social provisions related to the supervisory working alliance. Counsellor education and supervision, 42: $203-$
218.

Wijnnberg \& Schwartz, 1977 Models of Student Supervision: The Apprentice, Growth and Role Systems Models, Journal of Education for Social Work Vol. 13, No. 3, Fall 1977 